\title{
Human umbilical cord blood mononuclear cells and chorionic plate-derived mesenchymal stem cells promote axon survival in a rat model of optic nerve crush injury
}

\author{
SOKJOONG CHUNG ${ }^{1}$, SEUNGSOO RHO ${ }^{1}$, GIJIN KIM ${ }^{2}$, SO-RA KIM ${ }^{2}$, \\ KWANG-HYUN BAEK ${ }^{2}$, MYUNGSEO KANG ${ }^{3,4}$ and HELEN LEW ${ }^{1}$
}

Departments of ${ }^{1}$ Ophthalmology, ${ }^{2}$ Biomedical Science and ${ }^{3}$ Laboratory Medicine, CHA Bundang Medical Center,
CHA University; ${ }^{4}$ CHA Medical Center Cord Blood Bank, Seongnam-si, Gyeonggi-do, Republic of Korea

Received November 19, 2015; Accepted February 11, 2016

DOI: $10.3892 /$ ijmm.2016.2532

\begin{abstract}
The use of mesenchymal stem cells (MSCs) in cell therapy in regenerative medicine has great potential, particularly in the treatment of nerve injury. Umbilical cord blood (UCB) reportedly contains stem cells, which have been widely used as a hematopoietic source and may have therapeutic potential for neurological impairment. Although ongoing research is dedicated to the management of traumatic optic nerve injury using various measures, novel therapeutic strategies based on the complex underlying mechanisms responsible for optic nerve injury, such as inflammation and/ or ischemia, are required. In the present study, a rat model of optic nerve crush (ONC) injury was established in order to examine the effects of transplanting human chorionic plate-derived MSCs (CP-MSCs) isolated from the placenta, as well as human UCB mononuclear cells (CB-MNCs) on compressed rat optic nerves. Expression markers for inflammation, apoptosis, and optic nerve regeneration were analyzed, as well as the axon survival rate by direct counting. Increased axon survival rates were observed following the injection of CB-MNCs at at 1 week post-transplantation compared with the controls. The levels of growth-associated protein-43 (GAP-43) were increased after the injection of CB-MNCs or CP-MSCs compared with the controls, and the expression levels of hypoxia-inducible factor- $1 \alpha$ (HIF-1 $\alpha$ ) were also significantly increased following the injection of CB-MNCs or CP-MSCs. ERM-like protein (ERMN) and SLIT-ROBO Rho GTPase activating protein 2 (SRGAP2) were found to be expressed in the optic nerves of the CP-MSC-injected rats with ONC injury.
\end{abstract}

Correspondence to: Dr Helen Lew, Department of Ophthalmology, CHA Bundang Medical Center, CHA University, 59 Yatap-ro, Bundang-gu, Seongnam-si, Gyeonggi-do 463-712, Republic of Korea E-mail: eye@cha.ac.kr

Key words: optic nerve, placenta, stem cells, traumatic optic neuropathy, umbilical cord blood mononuclear cells
The findings of our study suggest that the administration of CB-MNCs or CP-MSCs may promote axon survival through systemic concomitant mechanisms involving GAP-43 and HIF-1 $\alpha$. Taken together, these findings provide further understanding of the mechanisms repsonsible for optic nerve injury and may aid in the development of novel cell-based therapeutic strategies with future applications in regenerative medicine, particularly in the management of optic nerve disorders.

\section{Introduction}

Traumatic optic nerve injury is one of the most common neuropathies, affecting an increasing number of individuals worldwide and leading to the loss of neural cells in the eyes (1). The 'optic nerve,' the bundle of retinal ganglion cell (RGC) axons, is part of the central nervous system (CNS). RGCs are the output neurons that relay visual signals from the eye, extending along axons via the optic nerve to the brain. Traumatic optic neuropathies often lead to the retrograde degeneration and apoptosis of RGCs, potentially resulting in visual impairment and neurological dysfunction. For the treatment of traumatic optic neuropathy, it is necessary to promote axonal regeneration or prevent the death of injured neurons (2).

Establishing an effective animal model of optic nerve injury is important in order to better understand the mechanisms responsible for RGC degeneration and neuroprotection, and to further explore novel drug targets and treatment options for optic nerve functional recovery and regeneration. 'Optic nerve crush' (ONC) injury is a popular experimental model of traumatic optic nerve injury, typically characterized by sudden visual loss attributable to irreversible disturbances (1).

Regenerative medicine using human stem cells is a new and promising field which has the potential to for use in the treatment of various intractable diseases and damaged organs, including difficult-to-treat optic nerve diseases. Many scientists have demonstrated the abilities of various stem cells to ameliorate optic nerve damage (1-7) in animal models of optic nerve compression. Mesenchymal stem cells (MSCs) have great potential for use as cell therapy in regenerative medicine, including the treatment of nerve injury. Umbilical cord blood (UCB) mononuclear cells (CB-MNCs), which reportedly 
contain stem cells (8-12), have been widely used as a hematopoietic source, and have been shown to possess therapeutic potential for repairing neurological impairment (13-19). A previous study using an experimental animal model of ONC injury demonstrated the therapeutic effects of intravitreally administering CB-MNCs, with the incorporation of these cells into the neurological lesion (1). UCB cells have been banked worldwide, and no harmful effects have been reported with their use $(10,11)$. In terms of the therapeutic management of optic nerve injury, UCB has potential based on its known neuroprotective properties due to its anti-inflammatory and anti-apoptotic activities $(10,11,13,18)$.

In contrast to other MSCs, including bone marrowderived MSCs (BM-MSCs) and adipose tissue-derived MSCs (AD-MSCs), placenta-derived mesenchymal stem cells (PD-MSCs) are obtainable in massive numbers and have potent immunological properties $(20,21)$. Human PD-MSCs were classified over the past decade and have become the focus of attention in stem cell research (22) due to the following reasons: they were the first of the adult stem cells to appear, they have great potential for proliferation, differentiation and self-renewal, they are readily available, and they are easily procured without any invasive procedures $(10,23)$. Several types of PD-MSCs, such as amnion-derived MSCs (AMSCs), chorionic plate-derived MSCs (CP-MSCs), Wharton's jelly-derived MSCs (WJ-MSCs) and chorionic villiderived MSCs (CV-MSCs), have been described and may exert therapeutic effects through anti-fibrotic mechanisms (20). It has been confirmed that the cells derived from the chorioamniotic membrane of the full term placenta are MSCs and these cells have been characterized as CP-MSCs and have been shown to exert several therapeutic effects $(10,20,21,23)$.

Although research dedicated to the management of traumatic optic nerve injury using various measures is ongoing, novel therapeutic strategies based on the complex underlying major mechanism(s) responsible for this type of injury, such as inflammation and/or ischemia, are required.

Thus, in the present study, we established an animal model of traumatic optic neuropathy (namely ONC injury) using Sprague-Dawley (SD) rats and examined the variations in axon counts. Using this rat model, we aimed to examine the efficacy of treatment using UCB (namely CB-MNCs), compared to treatment using CP-MSCs.

\section{Materials and methods}

Animals. All experimental procedures conformed to the Association for Research in Vision and Ophthalmology (ARVO) Statement regarding the Use of Animals in Ophthalmic and Vision Research. Animal protocols were approved by the Institutional Animal Care and Use Committee of CHA Bundang Medical Center (Seongnam-si, Korea).

All animals were housed in a standard animal facility with food and water provided ad libitum at a constant temperature of $21^{\circ} \mathrm{C}$. Six-week-old male SD rats (Orient Bio Inc., Seongnam-si, Korea) were maintained in an air-conditioned animal house under specific pathogen-free conditions. The animals were maintained for at least 1 week in this environment prior to being subjected to the surgical procedures, which were performed on one eye of each rat, while the contralateral eye served as the sham-operated control. Topical ophthalmic ointment (Ciproxacin, Tarivid ${ }^{\circledR}$; Santen Pharmaceutical, Co, Tokyo, Japan) was applied immediately after the surgical procedures.

Establishment of a ratmodel of ONC injury. Ninety male SD rats (Orient Bio Inc.), weighing 200-250 g, were anesthetized by an intraperitoneal injection of Zoletil (1:1 tiletamine:zolazepam; $30 \mathrm{mg} / \mathrm{kg}$ ) and Rompun (xylazine $10 \mathrm{mg} / \mathrm{kg}$ ). Following the topical application of $0.5 \%$ proparacaine hydrochloride, a lateral canthotomy and conjunctival incision were made, and the tissues surrounding the optic nerve were dissected such that the optic nerve was exposed without damaging the adjacent blood supply. Extra-fine self-closing forceps were used to crush the optic nerve $2 \mathrm{~mm}$ behind the globe for $5 \mathrm{sec}$. The canthal incision was then sutured. To examine the temporal response following ONC injury and to establish the model of ONC injury, 15 rats were administered a lethal dose of anesthetic at 1,2 or 4 weeks ( $n=5$ rats for each time point).

Assessment of axonal density and axon survival ratio. After 1, 2 and 4 weeks, the eyeballs were enucleated to assess the axonal density following an intraperitoneal injection of Zoletil (1:1 tiletamine:zolazepam; $30 \mathrm{mg} / \mathrm{kg}$ ) and Rompun (xylazine, $10 \mathrm{mg} / \mathrm{kg}$ ). The excised axons and the eyeballs were fixed in Karnovsky's solution, processed with $1 \%$ osmium tetroxide and embedded in Epon-Araldite resin (Ladd Research Industries, Burlington, VT, USA). Semi-thin $(<1.0 \mu \mathrm{m})$ cross-sections of the optic nerve (obtained from the midpoint of the sample, approximately $1 \mathrm{~mm}$ from the stump) were stained with $1 \%$ toluidine blue in $1 \%$ sodium borate. Digital images were obtained at x40 magnification using a light microscope (Olympus BX40; Olympus Optical Co. Ltd., Tokyo, Japan) for the histological examination of axonal density using ImageJ software $(\mathrm{NIH}$, http://rsb.info.nih.gov/ij/index.html).

We regarded the following axons as non-viable: i) visible swollen axons; ii) shrunken axons or axons with layer-splitting of myelin sheaths; and iii) extensive fibrotic axons. The number of the viable axons was counted and axon survival rates were defined as the axon density ratio between the normal side and the ONC injured side in each SD rat at the time of evaluation.

Preparation of $C B-M N C s$. Human heterogeneic UCB units were selected from the affiliated UCB bank, CHA Medical Center Cord Blood Bank (Seongnam-si, Korea). The out-of-specification UCB units consisted of $>3 \times 10^{7} / \mathrm{kg}$ total nucleated cells, which were washed to eliminate dimethyl sulfoxide, and the $\mathrm{CB}-\mathrm{MNCs}$ were counted. Prior to the administration of UCB (CB-MNCs), human leukocyte antigen (HLA) typing of the CB-MNCs, vs. the CP-MSCs, was performed; specifically, HLA-A -B, -C (\#555552, BD Biosciences, San Diego, CA, USA), HLA-DR (\#555811, BD Biosciences) and HLA-G (\#ab7904, Abcam, Cambridge, MA, USA) typing (Fig. 1).

Cultivation of CP-MSCs. Sample collection and use for research purposes were approved by the Institutional Review Board of CHA General Hospital, Seoul, Korea. All participants provided written informed consent prior to sample collection. The placentas were collected from female subjects who were free of medical, obstetric and surgical complications and who 
delivered at term (>37 gestational weeks). The CP-MSCs were harvested as previously described (22). Briefly, the CP-MSCs were collected from the inner side of the chorioamniotic membrane of the placenta and treated with $0.5 \%$ collagenase IV (C7661; Sigma-Aldrich, St. Louis, MO, USA) and cultured in MEM- $\alpha$ modification (\#32561; Gibco-BRL, NY, USA) supplemented with $10 \%$ fetal bovine serum (FBS, \#16000-044), $1 \%$ penicillin/streptomycin (\#15140-122) (all from Invitrogen, Carlsbad, CA, USA), $25 \mathrm{ng} / \mathrm{ml}$ human fibroblast growth factor-4 (hFGF-4; \#AF-100-31; Peprotech, Inc., Rocky Hill, NJ, USA) and $1 \mu \mathrm{g} / \mathrm{ml}$ heparin (H3149; Sigma-Aldrich).

In addition, the normal fibroblast cell line, WI-38, was purchased from ATCC (\#CCL-75, ATCC; Manassas, VA, USA). The cells were cultured in $\alpha$-MEM containing $10 \% \mathrm{FBS}$, $1 \%$ penicillin/streptomycin (P/S; $100 \mathrm{mg} / \mathrm{ml}$, Gibco-BRL), and 2 mM L-glutamine (Gibco-BRL).

FACS analysis. To analyze the expression of HLA surface markers, the CB-MNCs and CP-MSCs ( $10^{6}$ cells) were collected and washed with PBS containing $2 \%$ FBS. They were then incubated with isotype control immunoglobulin $\mathrm{G}(\mathrm{IgG})$ or antigen-specific antibodies [HLA-ABC (BD Biosciences), HLA-DR (BD Biosciences) and HLA-G (Abcam)] as well as fluorescence-conjugated anti-human $\mathrm{IgG}$ antibodies (1:200; , \#550931; BD Biosciences) for $30 \mathrm{~min}$ at room temperature. They were then stained with $5 \mathrm{ng} / \mathrm{ml}$ propidium iodide (\#4170; Sigma-Aldrich) to identify non-viable cells. FACS analysis was performed using a FACSCalibur Flow Cytometer (\#342975; BD Biosciences). The characterization of CP-MSCs (passages 8-10) is standard in our laboratory and has been proven desirable (24).

Stem cell injection. To analyze the engraftment of the cells, the CB-MNCs and the CP-MSCs were labeled using a PKH26 Red Fluorescent Cell Linker kit (MINI-26; Sigma-Aldrich) according to the manufacturer's instructions. The procedures are standard in our laboratory and have been proven efficient (24). The PKH26-labeled CP-MSCs $\left(10^{6}\right.$ cells, passage $8-10,0.5 \mathrm{ml})$ and PKH26-labeled CB-MNCs $\left(10^{6}\right.$ cells, $0.5 \mathrm{ml}$ ) were each injected into the left internal carotid artery of each animal $(n=30)$. Non-transplanted (NTP) rats $(n=15)$ were injected with an equal volume of normal saline alone as the sham-operated controls.

To determine the stem cell response, the animals were euthanized at 1, 2 or 4 weeks after the cell injection. The eyeballs were enucleated to assess the axon survival ratio and the immunohistochemical evaluation of the normal right side and the ONC injured left side in each rat. The optic nerves were collected at 1, 2 or 4 weeks post-injection from the animals in each of the 3 groups (NTP group, CB-MNC-transplanted group and CP-MSC-transplanted group). In addition, liver, lung and kidney specimens were obtained from 10 rats from the groups injected with the stem cells groups following enucleation at 1 week post-implantation. Liver, lung and kidney samples were embedded in Tissue-Tek OCT compound (Sakura Finetechnical Co., Ltd., Tokyo, Japan) to observe the infiltration of the injected stem cells following the transplantation of the CP-MSCs or CB-MNCs. Cryostat sections (10 $\mu$ m-thick) were assessed for PKH26-labeled cells using a fluorescence microscope.
Reverse transcription-quantitative polymerase chain reaction (RT-qPCR). The growth-associated protein-43 (GAP-43), and hypoxia-inducible factor- $1 \alpha(\mathrm{HIF}-1 \alpha)$ mRNA levels were measured by RT-qPCR. Equal amounts of protein from individual animals were pooled from the rats in the control (NTP) group $(n=15)$, the rats in the CP-MSCtransplanted group at 1 week $(n=10)$, the CP-MSC-transplanted group at 2 weeks $(n=10)$, the CP-MSC-transplanted group at 4 weeks $(n=10)$, as well as the rats in the CB-MNC-transplanted group at 1 week $(n=10)$, the CB-MNC-transplanted group at 2 weeks $(n=10)$ and the rats in the CB-MNC-transplanted group at 4 weeks $(n=10)$. Total RNA was isolated using TRIzol reagent. The concentration and quality of the RNA were determined using an ND-1000 spectrophotometer (NanoDrop, Waltham, MA, USA). Reverse-transcription to cDNA was conducted using the iScript cDNA synthesis kit (Bio-Rad Laboratories, Hercules, CA, USA) according to the manufacturer's instructions. The cDNA used for qPCR was normalized to $\beta$-actin. qPCR was performed using IQ SYBR-Green supermix (Bio-Rad Laboratories). Gene expression was quantified using the $\Delta \mathrm{CT}$ method. All reactions were performed in triplicate. Data are expressed as the means \pm SD of triplicate experiments.

Histological examination. Enucleation was performed to allow the pathological examination of the optic nerve. Tissue slices (5- $\mu \mathrm{m}$-thick) were cut and fixed in $4 \%$ paraformaldehyde. The tissue slices were then embedded in paraffin. The sections were dipped into gradient ethanol, stained with hematoxylin for $10 \mathrm{~min}$, differentiated in $1 \%(\mathrm{v} / \mathrm{v})$ hydrochloric acid alcohol for 5-10 sec, incubated in insaturated lithium carbonate solution for 5-10 sec, and stained with eosin for $10 \mathrm{~min}$. The sections were rinsed with distilled water for each interval step. The sections were then dehydrated with gradient ethanol, cleared with xylene, mounted with neutral gum, dried and observed for the general morphology and composition of the optic nerve using light microscopy. Immunohistochemical staining was performed on the $5-\mu$ m-thick sections, cut from formalin-fixed, paraffin wax-embedded tissues, using the anti-human nuclei and chromosomes, histone $\mathrm{H} 1$ protein antibody (Cat. no. MAB1276, mouse monoclonal, clone 1415-1, 1:200 dilution; Millipore, Billerica, MA, USA). The visualization system used was the BenchMark XT with heat-induced epitope retrieval (CC1 solution) and the ultraView Universal DAB Detection kit (all from Ventana, Tucson, AZ, USA).

RNA assay. The isolated optic nerves, including the crush lesion were homogenized using TRIzol reagent (Invitrogen, Carlsbad, CA, USA) for RNA extraction. To synthesize the cDNA, $3 \mu \mathrm{g}$ total RNA from each sample was reverse transcribed using SuperScript III reverse transcriptase (Invitrogen). RT-PCR was performed using the Solg 2X Taq PCR Pre-Mix (Solgent, Daejeon, Korea). The PCR conditions were as follows: initial melting $\left(95^{\circ} \mathrm{C}, 2 \mathrm{~min}\right), 40$ cycles of amplification $\left(95^{\circ} \mathrm{C}\right.$ for $20 \mathrm{sec}, 45-55^{\circ} \mathrm{C}$ for $40 \mathrm{sec}$, and $72^{\circ} \mathrm{C}$ for $\left.1 \mathrm{~min}\right)$ and a final extension $\left(72^{\circ} \mathrm{C}\right.$ for $\left.5 \mathrm{~min}\right)$. $\beta$-actin was amplified for normalization using the following PCR conditions: initial melting $\left(95^{\circ} \mathrm{C}\right.$ for $2 \mathrm{~min}), 40$ cycles of amplification $\left(95^{\circ} \mathrm{C}\right.$ for $20 \mathrm{sec}, 50^{\circ} \mathrm{C}$ for $40 \mathrm{sec}$, and $72^{\circ} \mathrm{C}$ for $\left.1 \mathrm{~min}\right)$ and a final extension $\left(72^{\circ} \mathrm{C}\right.$ for $5 \mathrm{~min})$. The ERM-like protein $(E R M N)$, lecithin-retinol acyltransferase (LRAT) and SLIT-ROBO Rho GTPase activating 
CP-MSCs
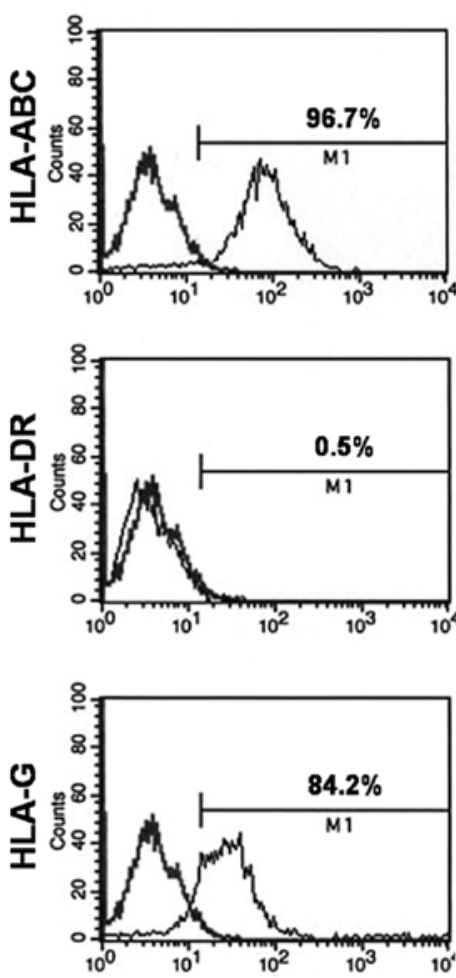

CB-MNCs
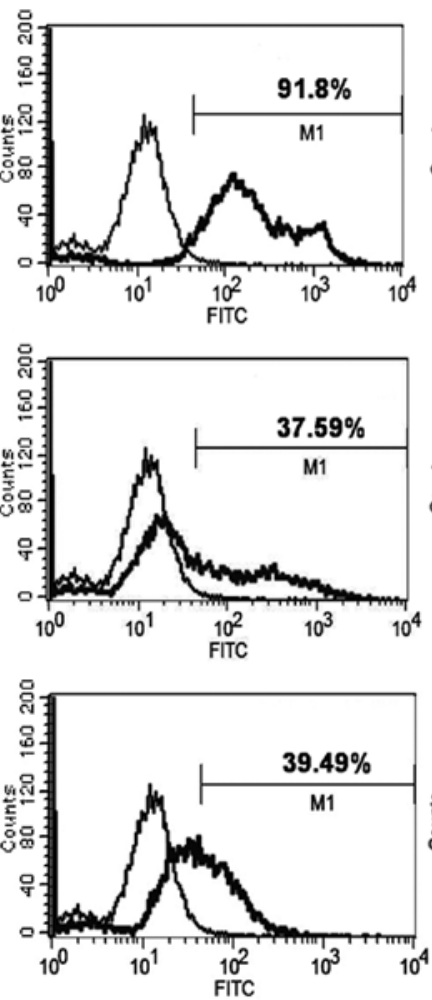

WI-38
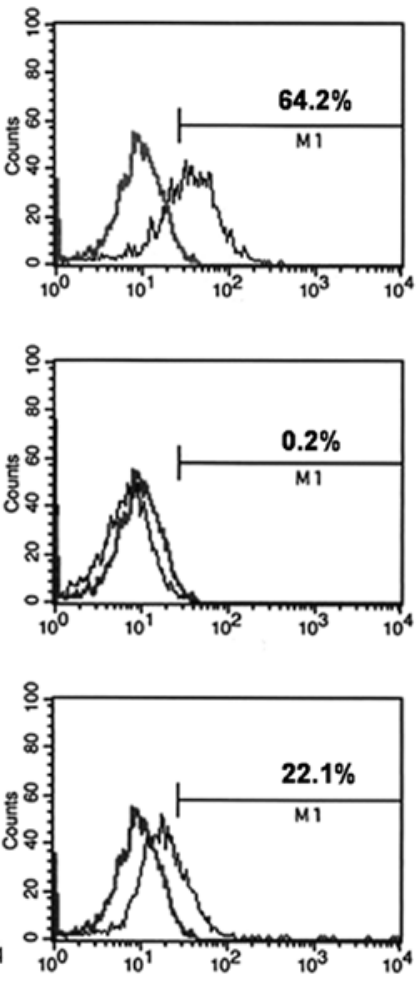

Figure 1.FACS analysis of the expression of HLA typing among chorionic plate-derived MSCs (CP-MSCs), umbilical cord blood mononuclear cells (CB-MNCs) and WI-38 cells. The percentages are indicated along with the fluorescence intensities.

protein 2 (SRGAP2) primer sets used were as follows: ERMNFP, 5'-AAA ACC CAG AAG AGA AAC-3' and RP, 5'-ATC ATT ATT GCA ATT ATC-3'; LRAT FP, 5'-AGG CGA CGT GCT GGA GGT-3' and RP, 5'-AGT GCT CGC AGT TGT TCC-3'; SRGAP2 FP, 5'-GAA TTT TTC CTG CAA CTG GA-3' and RP, 5'-AAT GAG CAT ATT TGG CTT TG-3'.

Western blot analysis. The optic nerve tissues were lysed in PRO-PREP solution (Intron, Seongnam-si, Korea). The protein lysates were loaded onto $10 \%$ sodium dodecyl sulfate-polyacrylamide gels, and the separated proteins were transferred onto polyvinylidene difluoride (PVDF) membranes, blocked, and then incubated with antibodies to SRGAP2 and ERMN (both from Abcam, Cambridge, UK), neurofilament (NF; Cell Signaling Technology, Danvers, MA, USA) and oncomodulin (OCM; Santa Cruz Biotechnology, Santa Cruz, CA, USA) overnight at $4^{\circ} \mathrm{C}$ at dilutions of $1: 200$ or $1: 1,000$. The membranes were washed and then incubated with anti-rabbit or anti-goat IgG secondary antibody (Santa Cruz Biotechnology) for $3 \mathrm{~h}$ at room temperature using an orbital shaker. After washing, the bands were detected using an enhanced chemiluminescence reagent (Bio-Rad Laboratories).

Statistical analysis. In the present study, statistical analyses were performed using SPSS software (version 19.0; IBM, Chicago, IL, USA) and Prism 5.0 (GraphPad Software, San Diego, CA, USA). Depending on the normality of the data, they are presented as the means \pm SD. Differences among the groups were analyzed using one-way ANOVA, followed by a Student's t-test. A p-value $<0.05$ was considered to indicate a statistically significant difference. ANOVA or the KruskalWallis and Mann-Whitney U tests were used to compare outcomes between independent groups, and a paired t-test was used to analyze intragroup differences.

\section{Results}

FACS analysis. Our results revealed differences in the expression levels of the HLA surface markers between the CP-MSCs and CB-MNCs. The CP-MSCs were negative for hematopoietic markers, such as HLA-DR, and positive for non-hematopoietic markers, such as HLA-ABC, similar to the WI-38 cells. Furthermore, the surface expression of HLA-G was detected in the CP-MSCs. However, the CB-MNCs were positive for hematopoietic markers, such as HLA-DR. The characterization of CP-MSCs (passages 8-10) is standard in our laboratory and has been proven desirable (Fig. 1).

Engraftment of $C B-M N C s$ and $C P-M S C s$. To confirm the infiltration of the injected CP-MSCs or CB-MNCs, liver, lung and kidney samples were examined. PKH26-labeled red fluorescent cells were observed in the liver, lungs and kidneys at 1 week post-transplantation (Fig. 2).

Axon survival ratio in the rat model of ONC injury. The axon survival rates were defined as the axon density ratio between the normal side and the ONC injured side in each rat at the time of sacrifice. Compared with the normal side, the axon density decreased significantly on the ONC injured side $(\mathrm{p}<0.05)$. In the rats with ONC injury, the axon survival rate was approxi- 


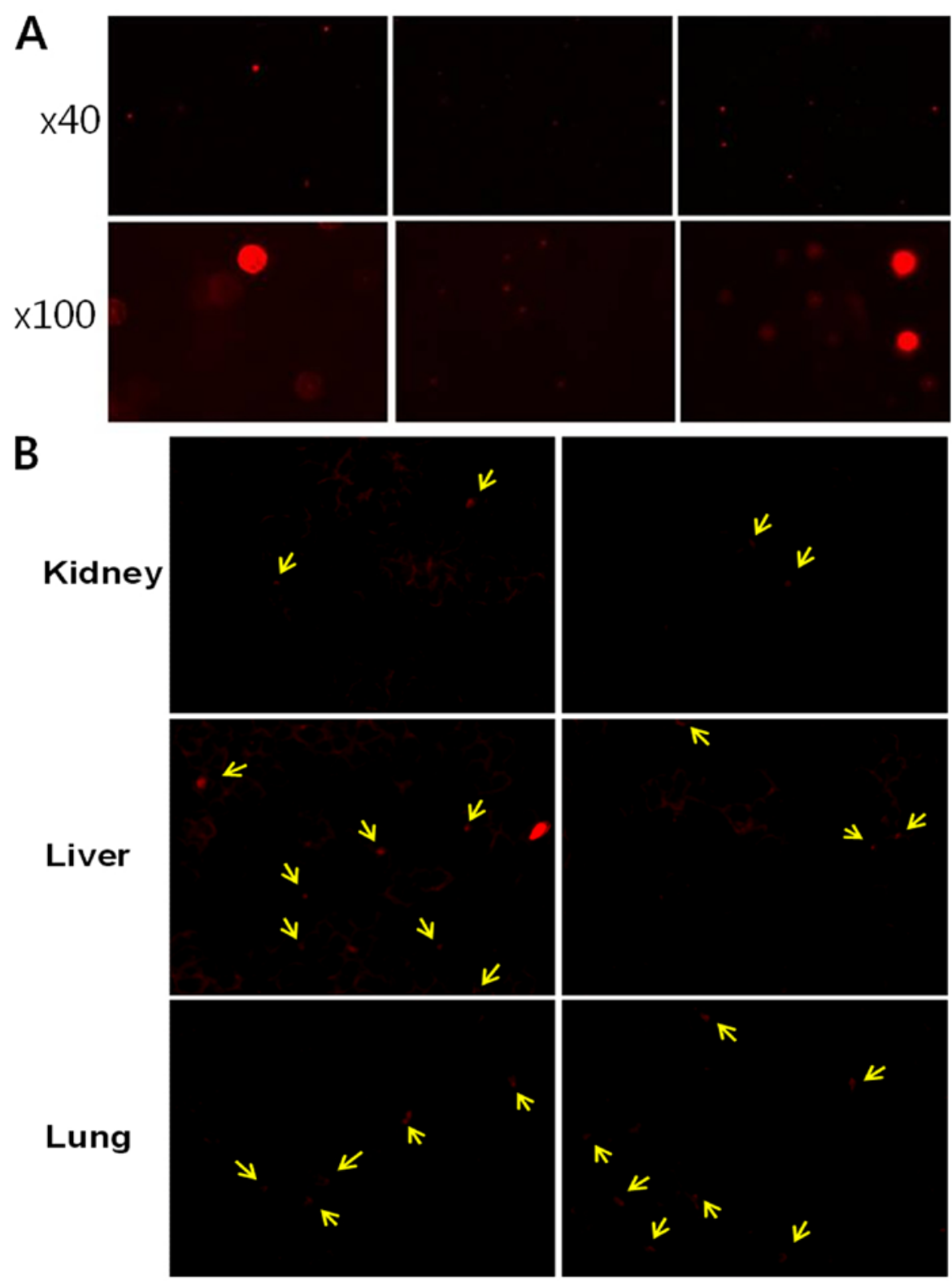

Figure 2. (A) Staining of umbilical cord blood mononuclear cells (CB-MNCs) using PKH26 fluorescence (left panel, prefixed; middle panel, fixed with methanol; right panel, fixed with 4\% paraformaldehyde). (B) Engraftment of PKH26-labeled CP-MSCs (left panel) and CB-MNCs (right panel) in the rat model of ONC injury. Arrows indicate PKH26-labeled cells engrafted onto target organs (x40 magnification, kidney, liver and lung samples).

mately $80 \%$ at 1 week and decreased to approximately $60 \%$ at 2 weeks and to approximately $40 \%$ at 4 weeks following ONC injury. The axon survival rates between 1 and 4 weeks differed significantly ( $\mathrm{p}=0.029)$ (Fig. $3 \mathrm{~B}$, control). In the rat model of ONC injury, the axon survival rate may be used as an outcome measure for evaluating diagnosis and treatment.

Axon survival ratios in rats with ONC injury following the injection of $C B-M N C s$ or $C P$-MSCs. Axon counting revealed the low survival rate in the NTP group compared to the CB-MNC group and CP-MSC group, with the representative images of each group at each time point shown in Fig. 3A. The axon survival rates were $75.1 \pm 18.05 \%$ at 1 week, $61.15 \pm 38.12 \%$ at 2 weeks and $38.08 \pm 26.02 \%$ at 4 weeks following ONC injury in the control group. Compared with the control group, the axon survival rates were $87.46 \pm 16.34 \%$ at 1 week $(\mathrm{p}<0.05)$, $48.56 \pm 17.92 \%$ at 2 weeks, and $42.68 \pm 30.13 \%$ at 4 weeks following ONC injury in the CB-MNC-transplanted group. The axon survival rates were $72.08 \pm 13.70 \%$ at 1 week, $48.17 \pm 19.57 \%$ at 2 weeks, and $39.96 \pm 24.88 \%$ at 4 weeks following ONC injury in the CP-MSC-transplanted group (Fig. 3B).

Thus, in this SD rat model of traumatic optic neuropathy (ONC injury), the axon survival ratio increased significantly at 1 week post CB-MNC transplantation.

$C B-M N C$ and $C P-M S C$ transplantation upregulates GAP-43 expression. Generally, an inflammatory response coincides with damage and repair processes in tissues, causing a hypoxic condition that acts as a triggering factor for cell damage and also as a necessary factor during optic nerve regeneration $(25,26)$. In this study, to investigate the potential anti-inflammatory effects of CB-MNC and CP-MSC transplantation, we analyzed neuronal regeneration in the optic nerve by measuring the expression levels of GAP-43 using RT-qPCR. In the rats in the 

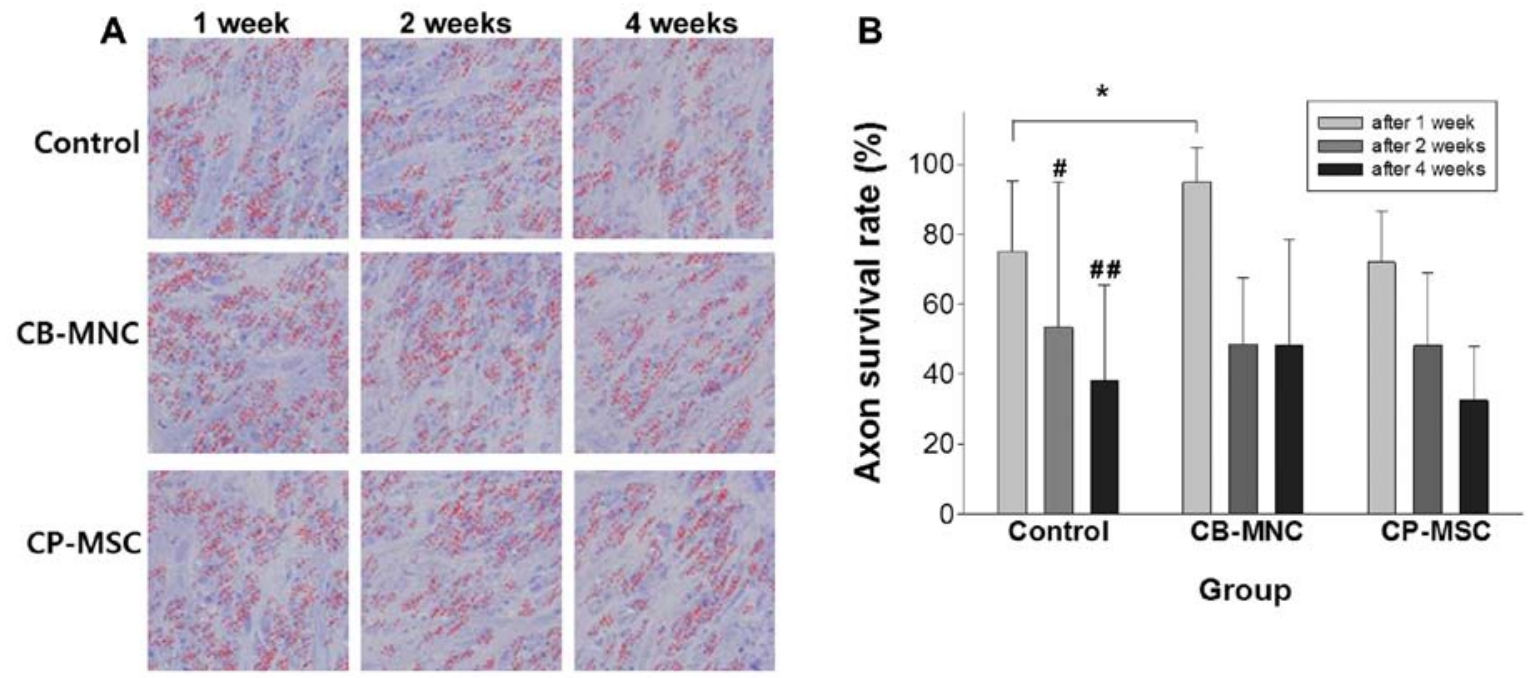

Figure 3. Therapeutic effects of transplantation of umbilical cord blood mononuclear cells (CB-MNCs) and chorionic plate-derived MSCs (CP-MSCs) in a rat model of optic nerve crush (ONC) injury. The optic nerves were obtained from the control group (non-transplanted group; upper panel), CB-MNC-transplanted group (CBMNC; middle panel) and CP-MSC-transplanted group (CP-MSC; lower panel) at 1,2 and 4 weeks after the internal carotid artery injection. (A) Following the injection of CB-MNCs or CP-MSCs, semi-thin cross-sections of the optic nerve were stained with $1 \%$ toluidine blue in $1 \%$ sodium borate. Axon counting was performed in the digital images at x40 magnification using a light microscope for the histological examination of axonal density using ImageJ software. (B) Following the injection of CB-MNCs or CP-MSCs, the axon survival rate was defined as the axon density ratio between the normal side and the ONC side in each rat at the time of sacrifice. Data are expressed as the means \pm SD from 5 rats from each group. ${ }^{*} \mathrm{p}<0.05 ;{ }^{\#} \mathrm{p}<0.05$, compared to 'normal side'; ${ }^{\# \prime} \mathrm{p}<0.05$, compared to 1 week.

NTP group, no significant difference was observed between the normal side and the ONC inuured side at 1 week post-injury. Furthermore, GAP-43 was expressed at low levels in the optic nerve in the NTP group rats, whereas the transplantation of the CP-MSCs resulted in a marked increase in GAP-43 expression in the ONC injured optic nerve at 1 week post transplantation (p<0.05; Fig. 4A). GAP-43 expression then decreased in the ONC injured side in the CB-MNC-transplanted group or CP-MSC-transplanted group compared to the NTP group at 4 weeks post-transplantation ( $\mathrm{p}<0.05$; Fig. $4 \mathrm{~A})$. These findings suggest that the transplantation of the CB-MNCs and CP-MSCs increases the expression of axonal growth-associated protein, mainly during the first stages of acute injury.

CB-MNC transplantation upregulates HIF-1 $\alpha$ expression. As HIF-1 $\alpha$ is a known trigger factor for adaptation and survivalrelated signal transduction (27), we investigated whether CB-MNCs or CP-MSCs induce its expression and activation. We found that in the CB-MNC-transplanted group, HIF-1 $\alpha$ expression was increased significantly compared with that in the NTP group rats at 1 week post-transplantation $(\mathrm{p}<0.05)$. Moreover, CB-MNC or CP-MSC transplantation markedly enhanced HIF-1 $\alpha$ expression in the normal and ONC injured sides until 2 weeks post-ONC injury $(\mathrm{p}<0.05)$. However, HIF-1 $\alpha$ expression was reduced again in the $\mathrm{ONC}$ injured side compared to the normal side in the CP-MSC- and CB-MNC-transplanted groups at 2 weeks post-transplantation ( $\mathrm{p}<0.05 ;$ Fig. $4 \mathrm{~B}$ ). HIF- $1 \alpha$ expression also decreased in the ONC injured side in both the CP-MSC- and CB-MNC-transplanted groups at 4 weeks posttransplantation $(\mathrm{p}<0.05$; Fig. 4B) These findings suggest that transplantation procedures may induce HIF-1 $\alpha$ expression, and the transplanted stem cells contribute to recovery of HIF-1a expression and possibly, neuronal survival in the injured optic nerve.
Histological examination of optic nerve tissue from rats with ONC injury following CP-MSC or CB-MNC transplantation. Sequential histological findings in the rat model of ONC injury following the injection of CB-MNCs and CP-MSCs using hematoxylin and eosin staining revealed subacute inflammation around the compression area compared with the controls in the optic nerve tissue 2 weeks post-CB-MNC injection. At 2 weeks post-CP-MSC injection, subacute inflammation was observed in the optic nerve tissue around the compression line, compared with that observed in the controls (Fig. 5A).

Immunohistochemical findings from the optic nerve tissue 5- $\mu \mathrm{m}$-thick) sections following the injection of CB-MNCs or CP-MSCs revealed limitations in detecting the presence of the surviving human MNCs, as it was difficult to identify human nuclei and chromosomes, stained as dark brown nuclei, around the compression area, compared with the control optic nerve, at 2 weeks post-CB-MNC injection. At 2 weeks postCP-MSC injection, it was also very difficult to identify dark brown nuclei around the compression area compared with the control optic nerve tissue (Fig. 5B).

RNA analysis of optic nerve tissue from rats with ONC injury post-CP-MSC or -CB-MNC injection by RT-PCR. To determine whether the regeneration of the optic nerve was induced by the injection of human cells or by natural rescue, we selected the human-specific genes, ERMN and LRAT, which are expressed specifically in the human retinal pigment epithelium (RPE) (28). These two genes differ in sequence between humans and mice. The expression of these two genes was expected to demonstrate stem cell differentiation and recovery of the damaged optic nerves. In addition, we determined the expression of the another human specific gene, $S R G A P 2$, which is involved in neuronal migration and differentiation $(29,30)$. To confirm that stem cells are still present in axons following the 

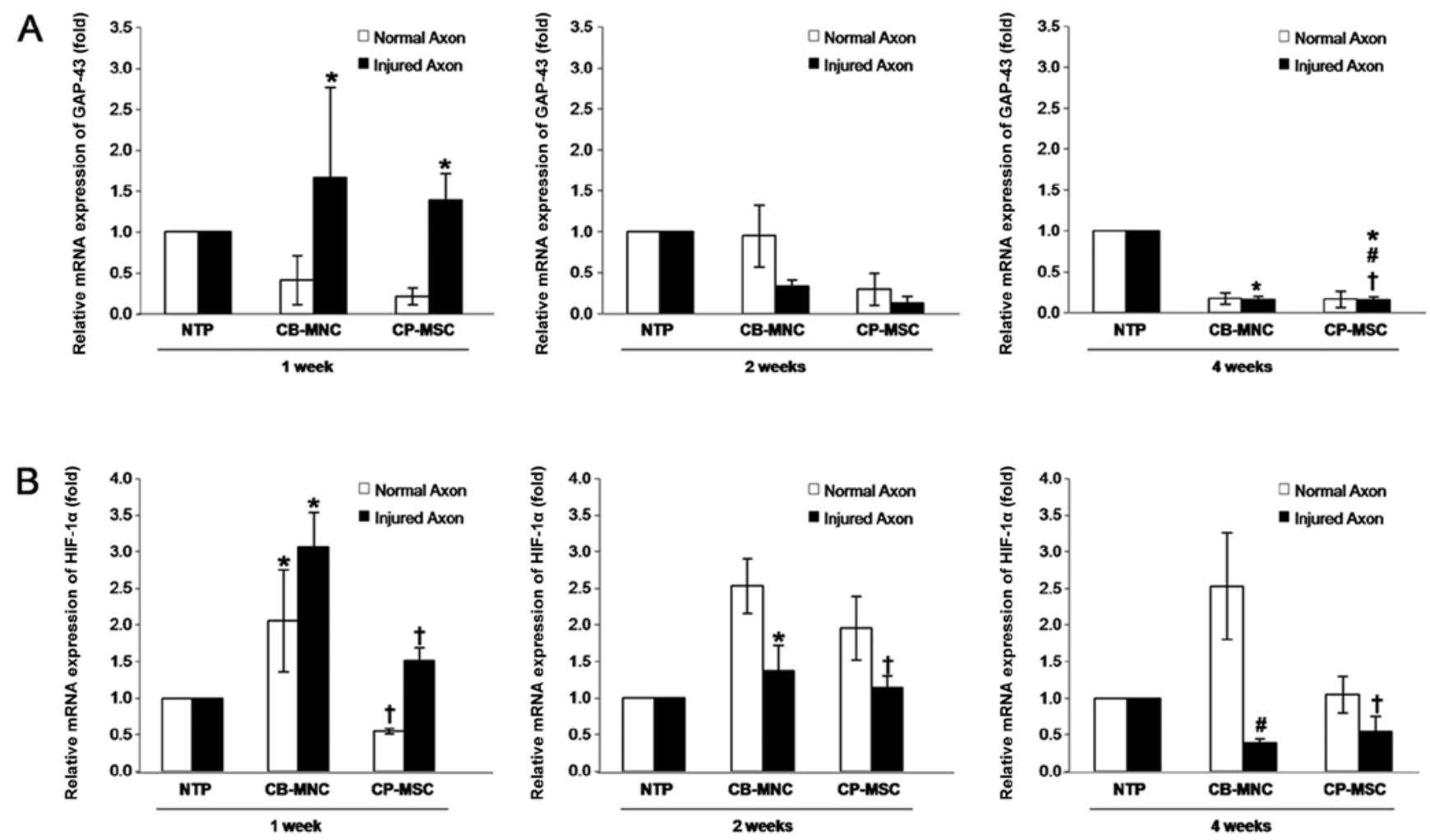

Figure 4. Expression and activity analyses of growth-associated protein-43 (GAP-43) and hypoxia-inducible factor-1 $\alpha$ (HIF-1 $\alpha$ ) in the optic nerves from a rat model of optic nerve crush (ONC) injury following umbilical cord blood mononuclear cell (CB-MNC) or chorionic plate-derived MSC (CP-MSC) transplantation Equal amounts of RNA were pooled from individual animals in the following groups and analyzed by RT-qPCR: the control non-transplanted group (NTP) at 1 week $(n=5), 2$ weeks $(n=5)$ and 4 weeks $(n=5)$, the CB-MNC-transplanted group (CB-MNC) at 1 week $(n=5)$, the CB-MNC-transplanted group at 2 weeks $(n=5)$, the CB-MNC-transplanted group at 4 weeks $(\mathrm{n}=5)$, as well as the CP-MSC-transplanted group (CP-MSC) at 1 week (n=5), the CP-MSC-transplanted group at 2 weeks $(\mathrm{n}=5)$, and the CP-MSC-transplanted group at 4 weeks $(\mathrm{n}=5)$. (A) Determination of the GAP-43 mRNA level using RT-qPCR. No significant differences were observed between the normal side and the ONC injured side in the rats in the NTP group at 1 week post-injury; significant differences were observed between the NTP and CP-MSC-transplanted groups in the ONC injured side at 1 week ( $\mathrm{p}<0.05)$, and between the CB-MNC-transplanted group or CP-MSC-transplanted group and NTP groups in the ONC injured side at 4 weeks post-transplantation (",\# $<<0.05)$. (B) The mRNA expression of $H I F-1 \alpha$ was determined. Significant differences were observed between the NTP and CB-MNC-transplanted groups at 1 week ( $\mathrm{p}<0.05)$, between the CB-MNC-transplanted group and NTP group in the ONC injured side, and the CB-MNC- and CP-MSC-transplanted groups at 2 weeks post-transplantation ( $\left.{ }^{*}+\mathrm{p}<0.05\right)$, and. between the normal side and ONC injured side in the CB-MSC- and CP-MSC-transplanted groups at 4 weeks post-transplantation (", $\mathrm{p}<<0.05)$. Data are expressed as the means \pm SD of triplicate experiments.
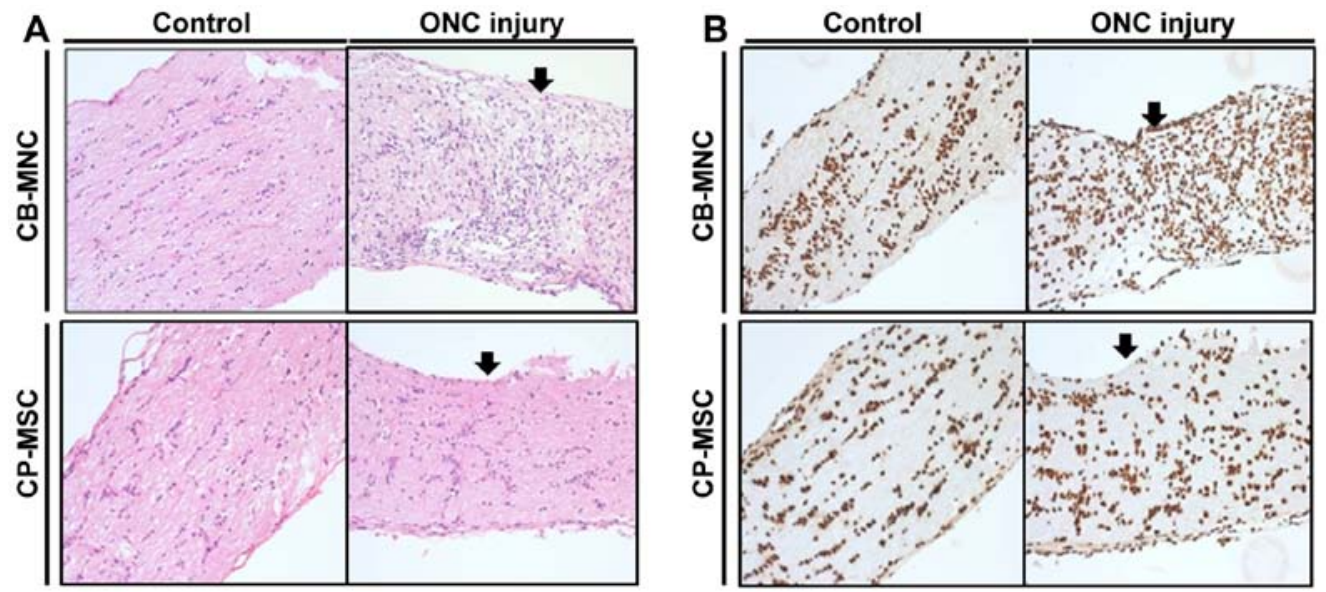

Figure 5. (A) Sequential histological findings using hematoxylin and eosin staining of optic nerve samples from a rat model of optic nerve compression after injection of umbilical cord blood mononuclear cells (CB-MNCs) or chorionic plate-derived MSCs (CP-MSCs). At 2 weeks post-CB-MNC injection, subacute inflammation was observed in the optic nerve around the compression area (arrow), compared with the controls. At 2 weeks post-CP-MSC injection, subacute inflammation was observed in the optic nerve around the compression line (arrow), compared with the control. (B) Immunohistochemical findings in the optic nerve after injection with CB-MNCs or CP-MSCs using 5- $\mu$ m-thick sections cut from formalin-fixed, paraffin wax-embedded tissue and the anti-human nuclei and chromosomes, histone H1 protein antibody (mouse monoclonal, clone 1415-1, 1:200 dilution). The BenchMark XT was used as the visualization system together with heat-induced epitope retrieval (CC1 solution) and the ultraView Universal DAB Detection kit. At 2 weeks post-CB-MNC injection, the presence of surviving human MNCs was hardly identified immunohistologically due to strong cross reactivity (dark brown nuclei around the compression area (arrow) in the optic nerve compared with the control). Similarly, at 2 weeks post-CP-MSC injection, the presence of surviving human MNCs was hardly identified immunohistologically due to strong cross reactivity (dark brown nuclei around the compression area (arrow) in the optic nerve compared with the control). All images are x400 magnification. Control, non-transplanted group; CB-MNC, CB-MNC-transplanted group; CP-MSC, CP-MSC-transplanted group. 
A

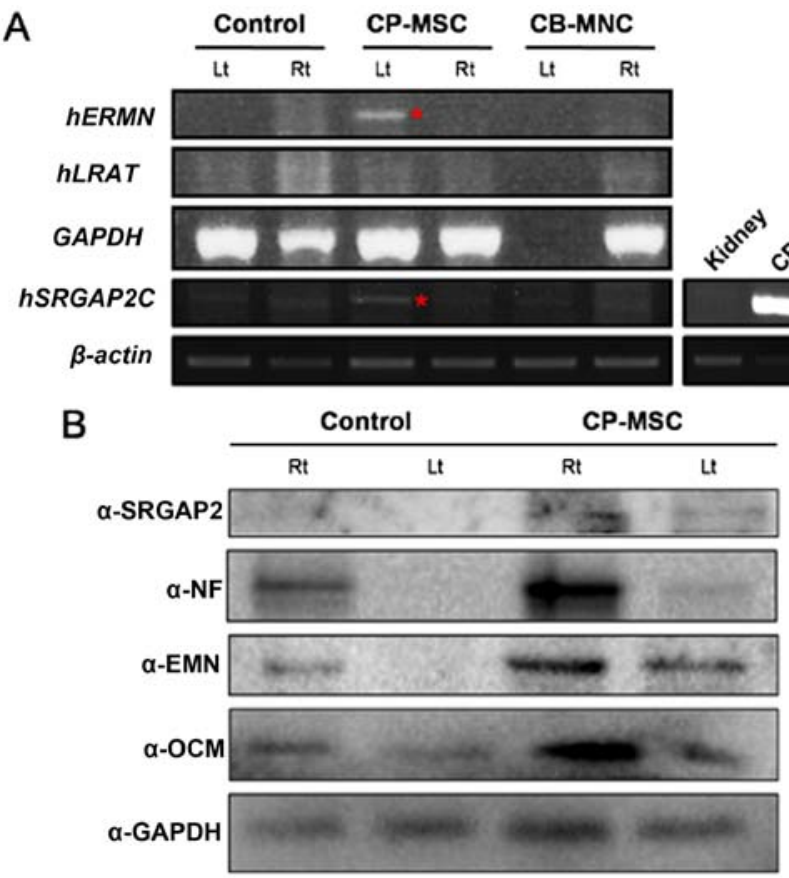

Figure 6. (A) RT-PCR analysis of human RNA in the optic nerves from a rat model of optic nerve crush (ONC) injury after umbilical cord blood mononuclear cell (CB-MNC) or chorionic plate-derived MSC (CP-MSC) transplantation. Equal amounts of RNA were pooled from individual animals of the following groups: non-transplanted group (NTP) at 1 week post-injury, CB-MNC-transplanted (CB-MNC) or CP-MSC-transplanted group (CP-MSC) at 1 week, and CB-MNC-transplanted or CP-MSC-transplanted group at 2 weeks post-transplantation. A human RNA signal was detected 1 week postCP-MSC injection (red asterisk). Actin was used as a loading control. Kidney samples from the rats in the NTP group and CP-MSC-transplatned group were used as the negative and positive controls, respectively (side panel, bottom right). (B) SRGAP2, NF, ERMN, and OCM levels were measured by western blot analysis using pooled protein samples from individual animals of the NTP group and CP-MSC-transplanted group at 2 weeks post-transplantation. GAPDH was used as loading control. Rt, right eye; Lt, left eye-optic nerve compression side; ERMN, ERM-like protein; LRAT, lecithin-retinol acyltransferase; SRGAP2, SLIT-ROBO Rho GTPase activating protein 2.

injection of the CP-MSCs, mRNA expression was evaluated using human specific primers. To assess mRNA expression, firstly, we isolated the optic nerves and homogenized these samples using TRIzol reagent. The RNA was extracted and subjected to cDNA synthesis. We then performed PCR using primers specific to ERMN, LRAT and SRGAP2. Also, human gene expression was confirmed in the kidney tissue obtained from the rats in the NTP group as a negative control and from the rats in the CP-MSC-transplanted group as a positive control (Fig. 6A). A human RNA signal was detected 1 week after the CP-MSC injection. These findings indicated that recovery from ONC injury was promoted by the injection of human stem cells. Western blot analysis was performed to measure the SRGAP2, NF, ERMN and OCM protein in the samples from CP-MSC-injected rats, indicating that recovery from ONC injury was promoted by human stem cell injection after 1 week (Fig. 6B). The results revealed that the transplantation of the CP-MSCs resulted in a reduction in ONC injury and damaged nerve function in the rats, suggesting that transplanted CP-MSCs may provide protection against traumatic injury to the optic nerve.

\section{Discussion}

The mature optic nerve is not able to regenerate when injured, leaving victims of traumatic nerve damage or diseases with irreversible vision loss. Research is currently focused on developing new treatment strategies to replenish damaged photoreceptors and retinal ganglion cells (RGCs), and to replace lost cells through transplants. The neuroprotective and regenerative potential of stem and progenitor cells from a variety of sources has been explored in models of retinal disease and ganglion cell loss (1).

In a previous study (31), the optic nerve regeneration process after an experimental axotomy performed on goldfish was very long in duration; it took approximately half a year for visual function to be fully recovered through synaptic refinement. The first period was a preparation period, within 5-6 days after the nerve lesion. The second period was an axonal elongation period, within 1-5 weeks after the nerve lesion. The third period involved synaptic connection and refinement in the tectum, within 1.5-4 months after the nerve lesion. The fourth period was a period of visual function recovery, within 5-6 months after the nerve lesion (31).

In this study, we counted the axons of the optic nerve observed in digital images obtained at $\mathrm{x} 40$ magnification using a light microscope and performed histological examinations of axonal density using ImageJ software. The loss of RGC axons in the optic nerves of glaucomatous eyes was previously assessed using an established semiquantitative optic nerve grading scheme with modfications under a light microscope $(32,33)$. The results of a previous study validate the use of both fixed-pattern sampling and targeted sampling for the estimation of axonal damage; however, it does not indicate that the latter method is superior for detection of axon loss in animals with minor damage (34). Recently, it was demonstrated that the results of the semi-automated method for counting axons in TEM images strongly correlated with those of conventional counting methods and exhibited excellent reproducibility $(34,35)$.

As previously demonstrated (36), the changes in GAP-43 expression observed in the fish retina during optic nerve regeneration reflect the state of visual function following nerve injury. GAP-43 is an exceptional molecule, which has short peak (7-20 days) and long plateau (50-120 days) phases in regrowing optic axons. However, the location of GAP-43 at the presynaptic terminal, which is the appropriate site for synaptic refinement of regrowing optic axons in the tectum, has not been considered. However, GAP-43 is a well known marker protein of growing axons during development and regeneration (36).

HIF-1 is a dimeric transcriptional complex that has been recognized primarily for its roles in the maintenance of oxygen and energy homoeostasis. HIF-1 functions as a master regulator of cellular and systemic homeostatic responses to hypoxia by activating the transcription of several genes, including those involved in energy metabolism, angiogenesis, apoptosis and those whose protein products increase oxygen delivery or facilitate metabolic adaptation to hypoxia. HIF-1 thus plays an essential role in embryonic vascularization, tumor angiogenesis and the pathophysiology of ischemic disease (37). The $\alpha$-subunit of HIF-1 is $\mathrm{O}_{2}$-labile and is degraded by proteasomes following prolyl hydroxylation and ubiquitination in normoxic cells (38). It has also been shown that HIF-1 $\alpha$ is involved in 
immune reactions (38). Immunomodulatory peptides, including interleukin-1 (IL-1) and tumor necrosis factor- $\alpha$ (TNF- $\alpha$ ) stimulate HIF-1-dependent gene expression even in normoxic cells. Both the hypoxia- and cytokine-induced activation of HIF-1 $\alpha$ increases the transcription of several genes encoding proteins that promote blood flow and inflammation, including vascular endothelial growth factor (VEGF), hemeoxygenase-1, endothelial and inducible nitric oxide synthetase (NOS) and cyclooxygenase-2 (COX-2) (38). Thus, the pharmacological activation of the HIF-1 complex may be desirable in ischemic and inflammatory disorders. In this study, an increase in HIF-1 $\alpha$ expression was observed following the intra-arterial injection of CB-MNCs or CP-MSCs at 1-2 weeks post-ONC injury. An increase in HIF-1 $\alpha$ expression was observed in the optic nerve injured sides resulting by the engrafted stem cells CP-MSCs at 2 weeks post-injury. Thus, stem cell supply may be beneficial for optic nerve axons to survive or recover from perineural vascular rupture and injury, as shown by the histological examination of the optic nerve.

The differentiation of seeded bone marrow-derived stem cells into mature vascular cells has previously been reported (39). Our results support the concept of the stem cell-mediated vascular regeneration and recovery from ONC injury. As we did identify small populations of hematopoietic progenitor cells used for seeding in the optic nerve, we detected human-derived stem cells in the perineural tissues from 1 week post-implantation. Our data suggest that CP-MSCs or CB-MNCs contribute to functional mature vascular regeneration through an inflammation-mediated process of vascular remodeling that is expedited by the secretion of CP-MSCs 1 week post-transplantation.

A direct mechanism involving implanted blood stem cells may still be involved in the recovery from neural or ischemic injury (40). A paracrine role for implanted blood stem cells in optic nerve recovery from injury has been demonstrated in studies reporting the rare occurrence of the transdifferentiation of various stem cells in vivo $(1,2)$. Studies examining the role of BM-MSCs in cell therapies for neurological or ischemic diseases have demonstrated that these cells do not differentiate into mature endothelial cells or regenerating tissues but, instead, function by releasing multiple cytokines that induce therapeutic angiogenesis, arteriogenesis and/or cytoprotection $(41,42)$.

Early data on transdifferentiation were likely attributed to misinterpretations of cell fusion (43-46), explaining the results of fluorescent membrane labeling techniques to track seeded stem cells. As discussed elsewhere, injected mononuclear cells, including monocytes/macrophages, are very adept at phagocytosis and cell fusion (45). To the best of our knowledge, murine cells have never been previously shown to express human antigens in vivo; however, there was strong cross reactivity observed between human cells and rat cells in our immunohistochemical staining experiment.

Additionally, our rat model enabled us to validate our immunohistochemical findings further using species-specific RT-qPCR. Seeded stem cells do not need to be incorporated directly into the vascular neotissue of the optic nerve. A certain type of cord blood stem cell (CB-SC) is multipotent and displays embryonic and hematopoietic characteristics. In previous studies, phenotypic characterization demonstrated that CB-SCs display embryonic cell markers [e.g., the transcription factors, octamer-binding transcription factor 4 (OCT-4) and Nanog, stage-specific embryonic antigen (SSEA)-3 and SSEA-4] and leukocyte common antigen CD45, but are negative for blood cell lineage markers (e.g., CD1a, CD3, CD4, CD8, CD11b, CD11c, CD13, CD14, CD19, CD20, CD34, CD41a, CD41b, CD83, CD90, CD105 and CD133) (8).

Additionally, CB-SCs display very low immunogenicity, as indicated by very low expression levels of major histocompatibility complex (MHC) antigens and failure to stimulate the proliferation of allogeneic lymphocytes (47).

It is generally recognized that no specific markers are readily available to identify non-hematopoietic stem cells, and CB-MNCs do not express hematopoietic stem cell markers, such as CD45 or CD14. However, CB-MNCs do display a surface marker profile similar to that of BM-MSCs. CB-MNCs express the stromal markers, CD9, CD10, CD29, CD44, CD73, CD90, CD166, as well as CD34, which is a cell-surface marker also expressed by endothelial cells. CD34(+) and total cell numbers also affect the outcomes in that greater cell numbers are associated with a 'better' response $(9,10)$.

The high potential of human placenta-derived stem cells for proliferation, differentiation and self-renewal has been considered; moreover, these cells are readily available and are easily procured without the need for invasive procedures (22). Among several types of PD-MSCs, CP-MSCs have been shown to differentiate into a variety of cell types and to possess effective anti-inflammatory properties $(20,21)$.

In terms of a novel therapeutic mechanism, intravenously infused CB-MNCs may act as remote bioreactors that eventually increase systemic anti-inflammatory or anti-ischemic cytokine production following sequestration into the lung microvasculature and parenchyma, and entrapment in the spleen by the direct stimulation of pulmonary macrophages and spleen-naïve $\mathrm{T}$ cells, as previously reported (11). The potential of infused stem cells to trigger autophagy to enhance regeneration and/or provide a therapeutic effect as cellular survival promoters is of interest $(23,48)$. A previous study focused on the direct mechanisms of CP-MSC therapeutic effectiveness, as well as on an indirect paracrine mechanism $(40,49)$. In this study, we provide direct evidence of the effects of CP-MSCs through incorporation into the optic nerves and increased axonal density, matched with enhanced neuronal regeneration markers and HIF.

To date, no reported study has indicated an effective cell therapy application method in acute optic nerve injury, to the best of our knowledge. A previous study on systemic CB-MNC administration for brain injury revealed no remaining cells 1 month after therapy, even with the continuous administration of cyclosporine (50). Thus, proximal injection of stem cells into the optic nerve may be the optimal route to maximize the collection of implanted stem cells around the optic nerve and minimize systemic spreading. However, we considered the application method for the high survival rate of stem cells after the systemic circulation, which provided the chance to enter the ophthalmic artery branching to pial vessels of optic nerves. Between the two methods of systemic injection, such as intravenously or intra-arterially, the majority of the stem cells injected intravenously are sequestered into the lungs and hardly enter to the arterial circulation to the ophthalmic artery. Among the proximal arteries branching to the ophthalmic artery, the 
internal carotid artery is relatively easily accessable and thick enough to engage the 26 gauge needle of injection.

Erythropoietin and granulocyte colony-stimulating factors have neuroprotective and neural-repair properties, particularly in ischemic brain injury (17). As certain studies have demonstrated the neuroprotective effects of cyclosporine and the activation of the AKT pathway, similar to erythropoietin, and that the combination of the two exerts even more potent neuroprotective effects, additional medications may also enhance the efficacy of CB-MNC transplantation $(11,19)$; however, neurotoxicity has been reported after long-term use of cyclosporine (51). As our study demonstrated, CB-MNCs and CP-MSCs indeed exerted protective effects against optic nerve injury in rats undergoing intra-arterial transplantation. However, the translation of these findings into clinical therapies has been achieved to a limited extent. Thus, further studies are warranted to delineate the long-term effects of CB-MNC and CP-MSC transplantation, to examine the differences in efficacy, injection time and stem cell numbers between the two cell types, and to fully elucidate the mechanisms of action of CB-MNCs and CP-MSCs, and thus to develop easier and safer methods of stem cell transplantation.

In conclusion, regenerative medicine using human stem cells is a novel and promising research field, which has potential for use in the treatment of various intractable diseases and damaged organs, including difficult-to-treat acute optic nerve injuries. Taken together, the findings of the present study demonstrate that CP-MSC or CB-MNC transplantation using a rat model of ONC injury ameliorates optic nerve damage and increases axon survival through incorporation in the optic nerve, as well as an increase in the HIF-1 $\alpha$ and GAP-43 expression levels.

\section{Acknowledgements}

The present study was supported by the National Research Foundation of Korea (NRF) grant funded by the Korean government (MSIP) (no. NRF-2014R1A2A2A01002617).

\section{References}

1. Zhao T, Li Y, Tang L, Li Y, Fan F and Jiang B: Protective effects of human umbilical cord blood stem cell intravitreal transplantation against optic nerve injury in rats. Graefes Arch Clin Exp Ophthalmol 249: 1021-1028, 2011.

2. Junyi L, Na L and Yan J: Mesenchymal stem cells secrete brainderived neurotrophic factor and promote retinal ganglion cell survival after traumatic optic neuropathy. J Craniofac Surg 26: 548-552, 2015.

3. Bull ND, Irvine KA, Franklin RJ and Martin KR: Transplanted oligodendrocyte precursor cells reduce neurodegeneration in a model of glaucoma. Invest Ophthalmol Vis Sci 50: 4244-4253, 2009

4. Aoki H, Hara A, Niwa M, Motohashi T, Suzuki T and Kunisada T: Transplantation of cells from eye-like structures differentiated from embryonic stem cells in vitro and in vivo regeneration of retinal ganglion-like cells. Graefes Arch Clin Exp Ophthalmol 246: 255-265, 2008

5. Bull ND, Limb GA and Martin KR: Human Müller stem cell (MIO-M1) transplantation in a rat model of glaucoma: survival, differentiation, and integration. Invest Ophthalmol Vis Sci 49: 3449-3456, 2008.

6. Levkovitch-Verbin H, Sadan O, Vander S, Rosner M, Barhum Y, Melamed E, Offen D and Melamed S: Intravitreal injections of neurotrophic factors secreting mesenchymal stem cells are neuroprotective in rat eyes following optic nerve transection. Invest Ophthalmol Vis Sci 51: 6394-6400, 2010.
7. Charalambous P, Hurst LA and Thanos S: Engrafted chicken neural tube-derived stem cells support the innate propensity for axonal regeneration within the rat optic nerve. Invest Ophthalmol Vis Sci 49: 3513-3524, 2008.

8. Canque B, Camus S, Dalloul A, Kahn E, Yagello M, Dezutter-Dambuyant C, Schmitt D, Schmitt C and Gluckman JC: Characterization of dendritic cell differentiation pathways from cord blood CD34(+)CD7(+)CD45RA(+) hematopoietic progenitor cells. Blood 96: 3748-3756, 2000.

9. Kao CH, Chen SH, Chio CC and Lin MT: Human umbilical cord blood-derived $\mathrm{CD} 34^{+}$cells may attenuate spinal cord injury by stimulating vascular endothelial and neurotrophic factors. Shock 29: 49-55, 2008.

10. Lee MW, Jang IK, Yoo KH, Sung KW and Koo HH: Stem and progenitor cells in human umbilical cord blood. Int J Hematol 92: 45-51, 2010

11. Min K, Song J, Kang JY, Ko J, Ryu JS, Kang MS, Jang SJ, Kim SH, Oh D, Kim MK, et al: Umbilical cord blood therapy potentiated with erythropoietin for children with cerebral palsy: a double-blind, randomized, placebo-controlled trial. Stem Cells 31: 581-591, 2013.

12. Newcomb JD, Sanberg PR, Klasko SK and Willing AE: Umbilical cord blood research: current and future perspectives. Cell Transplant 16: 151-158, 2007.

13. Lu D, Sanberg PR, Mahmood A, Li Y, Wang L, Sanchez-Ramos J and Chopp M: Intravenous administration of human umbilical cord blood reduces neurological deficit in the rat after traumatic brain injury. Cell Transplant 11: 275-281, 2002.

14. Meier C, Middelanis J, Wasielewski B, Neuhoff S, Roth-Haerer A, Gantert M, Dinse HR, Dermietzel R and Jensen A: Spastic paresis after perinatal brain damage in rats is reduced by human cord blood mononuclear cells. Pediatr Res 59: 244-249, 2006

15. Nan Z, Grande A, Sanberg CD, Sanberg PR and Low WC: Infusion of human umbilical cord blood ameliorates neurologic deficits in rats with hemorrhagic brain injury. Ann N Y Acad Sci 1049: 84-96, 2005.

16. Nikolic WV, Hou H, Town T, Zhu Y, Giunta B, Sanberg CD, Zeng J, Luo D, Ehrhart J, Mori T, et al: Peripherally administered human umbilical cord blood cells reduce parenchymal and vascular beta-amyloid deposits in Alzheimer mice. Stem Cells Dev 17: 423-439, 2008.

17. Papadopoulos KI, Low SS, Aw TC and Chantarojanasiri T: Safety and feasibility of autologous umbilical cord blood transfusion in 2 toddlers with cerebral palsy and the role of low dose granulocyte-colony stimulating factor injections. Restor Neurol Neurosci 29: 17-22, 2011.

18. Sun J, Allison J, McLaughlin C, Sledge L, Waters-Pick B, Wease $\mathrm{S}$ and Kurtzberg J: Differences in quality between privately and publicly banked umbilical cord blood units: a pilot study of autologous cord blood infusion in children with acquired neurologic disorders. Transfusion 50: 1980-1987, 2010.

19. Vendrame M, Cassady J, Newcomb J, Butler T, Pennypacker KR, Zigova T, Sanberg CD, Sanberg PR and Willing AE: Infusion of human umbilical cord blood cells in a rat model of stroke dose-dependently rescues behavioral deficits and reduces infarct volume. Stroke 35: 2390-2395, 2004.

20. Kim MJ, Shin KS, Jeon JH, Lee DR, Shim SH, Kim JK, Cha DH, Yoon TK and Kim GJ: Human chorionic-plate-derived mesenchymal stem cells and Wharton's jelly-derived mesenchymal stem cells: a comparative analysis of their potential as placenta-derived stem cells. Cell Tissue Res 346: 53-64, 2011.

21. Lee JM, Jung J, Lee HJ, Jeong SJ, Cho KJ, Hwang SG and Kim GJ: Comparison of immunomodulatory effects of placenta mesenchymal stem cells with bone marrow and adipose mesenchymal stem cells. Int Immunopharmacol 13: 219-224, 2012.

22. Parolini O, Alviano F, Bagnara GP, Bilic G, Bühring HJ, Evangelista M, Hennerbichler S, Liu B, Magatti M, Mao N, et al: Concise review: isolation and characterization of cells from human term placenta: outcome of the first international Workshop on Placenta Derived Stem Cells. Stem Cells 26: 300-311, 2008.

23. Jung J, Choi JH, Lee Y, Park JW, Oh IH, Hwang SG, Kim KS and Kim GJ: Human placenta-derived mesenchymal stem cells promote hepatic regeneration in $\mathrm{CCl}_{4}$-injured rat liver model via increased autophagic mechanism. Stem Cells 31: 1584-1596, 2013.

24. Lee MJ, Jung J, Na KH, Moon JS, Lee HJ, Kim JH, Kim GI, Kwon SW, Hwang SG and Kim GJ: Anti-fibrotic effect of chorionic plate-derived mesenchymal stem cells isolated from human placenta in a rat model of $\mathrm{CCl}_{4}$-injured liver: potential application to the treatment of hepatic diseases. J Cell Biochem 111: 1453-1463, 2010. 
25. Koriyama Y, Homma K, Sugitani K, Higuchi Y, Matsukawa T, Murayama D and Kato S: Upregulation of IGF-I in the goldfish retinal ganglion cells during the early stage of optic nerve regeneration. Neurochem Int 50: 749-756, 2007.

26. Benowitz LI and Yin Y: Optic nerve regeneration. Arch Ophthalmol 128: 1059-1064, 2010.

27. Tajima T, Goda N, Fujiki N, Hishiki T, Nishiyama Y, Senoo-Matsuda N, Shimazu M, Soga T, Yoshimura Y, Johnson RS and Suematsu M: HIF-1alpha is necessary to support gluconeogenesis during liver regeneration. Biochem Biophys Res Commun 387: 789-794, 2009.

28. Booij JC, ten Brink JB, Swagemakers SM, Verkerk AJ, Essing AH, van der Spek PJ and Bergen AA: A new strategy to identify and annotate human RPE-specific gene expression. PLoS One 5: e9341, 2010.

29. Guerrier S, Coutinho-Budd J, Sassa T, Gresset A, Jordan NV, Chen K, Jin WL, Frost A and Polleux F: The F-BAR domain of srGAP2 induces membrane protrusions required for neuronal migration and morphogenesis. Cell 138: 990-1004, 2009.

30. Dennis MY, Nuttle X, Sudmant PH, Antonacci F, Graves TA, Nefedov M, Rosenfeld JA, Sajjadian S, Malig M,Kotkiewicz H, et al: Evolution of human-specific neural SRGAP2 genes by incomplete segmental duplication. Cell 149: 912-922, 2012.

31. Kato S, Devadas M, Okada K, Shimada Y, Ohkawa M, Muramoto K, Takizawa N and Matsukawa T: Fast and slow recovery phases of goldfish behavior after transection of the optic nerve revealed by a computer image processing system. Neuroscience 93: 907-914, 1999.

32. Johnson TV, Bull ND, Hunt DP, Marina N, Tomarev SI and Martin KR: Neuroprotective effects of intravitreal mesenchymal stem cell transplantation in experimental glaucoma. Invest Ophthalmol Vis Sci 51: 2051-2059, 2010.

33. Ebneter A, Casson RJ, Wood JP and Chidlow G: Estimation of axon counts in a rat model of glaucoma: comparison of fixed-pattern sampling with targeted sampling. Clin Experiment Ophthalmol 40: 626-633, 2012.

34. Kim CY, Rho S, Lee NE, Lee CK and Sung YJ: Semi-automated counting method of axons in transmission electron microscopic images. Vet Ophthalmol 19: 29-37, 2016.

35. Rho S, Park I, Seong GJ, Lee N, Lee CK, Hong S and Kim CY: Chronic ocular hypertensive rat model using microbead injection: comparison of polyurethane, polymethylmethacrylate, silica and polystyene microbeads. Curr Eye Res 39: 917-927, 2014.

36. Kaneda M, Nagashima M, Mawatari K, Nunome T, Muramoto K, Sugitani K and Kato S: Growth-associated protein43 (GAP43) is a biochemical marker for the whole period of fish optic nerve regeneration. Adv Exp Med Biol 664: 97-104, 2010.

37. Vollmer S, Kappler V, Kaczor J, Flügel D, Rolvering C, Kato N, Kietzmann T, Behrmann I and Haan C: Hypoxia-inducible factor 1alpha is up-regulated by oncostatin $\mathrm{M}$ and participates in oncostatin M signaling. Hepatology 50: 253-260, 2009.

38. Hellwig-Bürgel T, Stiehl DP, Wagner AE, Metzen E and Jelkmann W: Review: hypoxia-inducible factor-1 (HIF-1): a novel transcription factor in immune reactions. J Interferon Cytokine Res 25: 297-310, 2005.
39. Kinnaird T, Stabile E, Burnett MS, Shou M, Lee CW, Barr S, Fuchs $S$ and Epstein SE: Local delivery of marrow-derived stromal cells augments collateral perfusion through paracrine mechanisms. Circulation 109: 1543-1549, 2004.

40. Gnecchi M, He H, Liang OD, Melo LG, Morello F, Mu H, Noiseux N, Zhang L, Pratt RE, Ingwall JS and Dzau VJ: Paracrine action accounts for marked protection of ischemic heart by Akt-modified mesenchymal stem cells. Nat Med 11: 367-368, 2005

41. Kinnaird T, Stabile E, Burnett MS, Lee CW, Barr S, Fuchs S and Epstein SE: Marrow-derived stromal cells express genes encoding a broad spectrum of arteriogenic cytokines and promote in vitro and in vivo arteriogenesis through paracrine mechanisms. Circ Res 94: 678-685, 2004

42. O'Neill TJ IV, Wamhoff BR, Owens GK and Skalak TC: Mobilization of bone marrow-derived cells enhances the angiogenic response to hypoxia without transdifferentiation into endothelial cells. Circ Res 97: 1027-1035, 2005.

43. Terada N, Hamazaki T, Oka M, Hoki M, Mastalerz DM, Nakano Y, Meyer EM, Morel L, Petersen BE and Scott EW: Bone marrow cells adopt the phenotype of other cells by spontaneous cell fusion. Nature 416: 542-545, 2002.

44. Uemura $\mathrm{R}, \mathrm{Xu} \mathrm{M}$, Ahmad $\mathrm{N}$ and Ashraf $\mathrm{M}$ : Bone marrow stem cells prevent left ventricular remodeling of ischemic heart through paracrine signaling. Circ Res 98: 1414-1421, 2006.

45. Alvarez-Dolado M, Pardal R, Garcia-Verdugo JM, Fike JR, Lee HO, Pfeffer K, Lois C, Morrison SJ and Alvarez-Buylla A: Fusion of bone-marrow-derived cells with Purkinje neurons, cardiomyocytes and hepatocytes. Nature 425: 968-973, 2003.

46. Nygren JM, Jovinge S, Breitbach M, Säwén P, Röll W, Hescheler J, Taneera J, Fleischmann BK and Jacobsen SE: Bone marrow-derived hematopoietic cells generate cardiomyocytes at a low frequency through cell fusion, but not transdifferentiation. Nat Med 10: 494-501, 2004.

47. Li C, Zhang W, Jiang X and Mao N: Human-placenta-derived mesenchymal stem cells inhibit proliferation and function of allogeneic immune cells. Cell Tissue Res 330: 437-446, 2007.

48. Sanchez CG, Penfornis P, Oskowitz AZ, Boonjindasup AG, Cai DZ, Dhule SS, Rowan BG, Kelekar A, Krause DS and Pochampally RR: Activation of autophagy in mesenchymal stem cells provides tumor stromal support. Carcinogenesis 32 : 964-972, 2011.

49. Lee Y, Jung J, Cho KJ, Lee SK, Park JW, Oh IH and Kim GJ: Increased SCF/c-kit by hypoxia promotes autophagy of human placental chorionic plate-derived mesenchymal stem cells via regulating the phosphorylation of mTOR. J Cell Biochem 114: 79-88, 2013.

50. Gornicka-Pawlak el B, Janowski M, Habich A, Jablonska A, Drela K, Kozlowska H, Lukomska B, Sypecka J and Domanska-Janik K: Systemic treatment of focal brain injury in the rat by human umbilical cord blood cells being at different level of neural commitment. Acta Neurobiol Exp (Wars) 71: 46-64, 2011.

51. Gijtenbeek JM, van den Bent MJ and Vecht CJ: Cyclosporine neurotoxicity: A review. J Neurol 246: 339-346, 1999. 